\title{
Competition of Reactive Signals and Thiol Modifications of Proteins
}

\author{
John T Hancock ${ }^{1^{*}}$, Tim J Craig ${ }^{1}$ and Matthew Whiteman ${ }^{2}$ \\ ${ }^{1}$ Department of Applied Sciences, University of the West of England, Bristol, UK \\ ${ }^{2}$ Department of Exeter Medical School, University of Exeter, Exeter, UK
}

*Corresponding author: John T Hancock, Department of Applied Sciences, University of the West of England, Bristol, UK, E-mail: john.hancock@uwe.ac.uk

Received date: October 11, 2017; Accepted date: November 03, 2017; Published date: November 10, 2017

Copyright: $\odot 2017$ Hancock JT, et al. This is an open-access article distributed under the terms of the Creative Commons Attribution License, which permits unrestricted use, distribution, and reproduction in any medium, provided the original author and source are credited.

\section{Commentary}

It is clear that cells are constantly bombarded by multiple signals, often initiating similar, or even conflicting, responses. Important players in this suite of signals are the reactive oxygen species (ROS), such as hydrogen peroxide $\left(\mathrm{H}_{2} \mathrm{O}_{2}\right)$, the reactive nitrogen species (RNS), such as nitric oxide (NO) and sulfur-based molecules, such as hydrogen sulfide $\left(\mathrm{H}_{2} \mathrm{~S}\right)$. These compounds are often involved in stress responses and dysfunction of these signaling systems is often involved in disease [1-3]. This commentary discusses the interactions of such signals, which was discussed in a previous paper [3]. It was argued that all these molecules are not acting in the same manner, and that $\mathrm{H}_{2} \mathrm{~S}$ was acting in a role which moderated the effects of ROS and NO.

Although many studies look at these compounds separately it is now apparent that these reactive compounds should be considered to be part of the same system $[3,4]$. There are several levels at which these molecules can interact. They may potentially react directly together, they may alter each other's accumulation, or they may compete for the same targets. Unless all this is considered the full extent and influence of such signals will not be understood.

It is clear that certain direct reactions are known [3]. For example, the ROS superoxide will react with NO to form peroxynitrite, which is itself a signaling molecule [5], and can react with potential signals such as $\mathrm{H}_{2} \mathrm{~S}$ [6]. $\mathrm{H}_{2} \mathrm{~S}$ and $\mathrm{NO}$ will react together to form nitrosothiols [7], again with potential signaling. Cells contain a high concentration of glutathione which helps to maintain a very reducing intracellular environment [8]. However, glutathione and NO can react together, forming S-nitrosoglutathione (GSNO) [9], which may act as a signal but also be a method of making NO more mobile through an organism. It always has to be appreciated that such reactions remove the molecule from the cell, so if NO reacts its bio-capacity to act as a signal goes down. The same argument applies to $\mathrm{H}_{2} \mathrm{O}_{2}, \mathrm{H}_{2} \mathrm{~S}$ and others. By reacting they are scavenging each other away from what is often thought of as their primary role: signaling.

Other reactive signals not considered in the original paper include hydrogen gas $\left(\mathrm{H}_{2}\right)$ [10]. Although direct reactions with reactive compounds has been ruled out in some cases, it is known to affect antioxidants levels in cells, so indirectly impinging on ROS and NO signaling, as well as having a role in the regulation of gene expression [11]. Other compounds worth considering here would include methane and ammonia [12]. Further consideration should also be given to the role of lipids in this system, for example NO can generate nitro-lipids which may be involved in signaling [13]. This is especially important when it has to be considered that for many of these reactive molecules their movement between cells will involve passage through membranes.

As well as direct interactions, it is known that some reactive compounds have an effect on each other's generation or removal. For example, $\mathrm{H}_{2} \mathrm{~S}$ modulates antioxidant levels, which is proposed to be important for post-harvest storage of fruit [14]. $\mathrm{H}_{2} \mathrm{~S}$ has also been shown to decrease the expression of Nox4, an NADPH oxidase responsible for increased ROS accumulation [15]. Therefore, as argued previously [3], $\mathrm{H}_{2} \mathrm{~S}$ seems to reduce the generation of ROS and at the same time increases its removal. In a similar manner, $\mathrm{H}_{2} \mathrm{~S}$ has been reported to inhibit nitric oxide synthase, so altering NO metabolism [16]. On the other hand NO and ROS sometimes need to work together in signaling pathways [17]. It can be seen therefore that numerous reactive molecules in signaling have complex and as yet not understood interactions.

Of critical importance is the effect any of these compounds have on proteins. Although various post-modifications can be considered here, such as NO reaction with tyrosine [18], the focus here is the reaction with thiol groups [3]. It is well recognized that $\mathrm{H}_{2} \mathrm{O}_{2}$ will react with thiol groups to form the sulphenic acid, sulphinic acid and sulfonic acid groups respectively as the $\mathrm{H}_{2} \mathrm{O}_{2}$ concentration increases. Lower oxidation states may be reversible and so such a change to the protein may be considered to be akin to phosphorylation. However, higher oxidation states (sulphonic acid) are thought to be irreversible modifications. Of importance here, $\mathrm{NO}$ (S-nitrosylation) [19] will react with thiols as will glutathione (S-glutathionylation) [20] and $\mathrm{H}_{2} \mathrm{~S}$ (Ssulfhydration) [21]. Therefore a competition is set up between the signaling molecules, with modified thiols being the target. It is almost certain that each of the modifications will have a different outcome, perhaps changing the activity or function of the protein in subtle ways. Which modification wins out at the end is dependent on the relative local concentration of the reactive signaling molecules present, as well as the local environment of the thiol being attacked. The latter will depend on the three dimensional locality of local amino acid groups, either from the same polypeptide or one closely associated with it, but it may also depend on the intracellular redox poise of the location of the protein [8].

One of the most important proteins to be a target in this way is tyrosine phosphatase, PTP [22]. This protein is instrumental in phosphorylation signaling and is inhibited by $\mathrm{H}_{2} \mathrm{O}_{2}$, but can also be regulated by $\mathrm{NO}$ and $\mathrm{H}_{2} \mathrm{~S}$ [23]. Therefore, inhibition of phosphatases is likely to increase phosphorylation levels of multiple proteins in the cell, highlighting the importance of the signaling by these reactive molecules.

Another enzyme which is also worth highlighting is glyceraldehyde 3-phosphate dehydrogenase (GAPDH). Although originally thought to be only involved in glycolysis it is now apparent that GAPDH can be post-translationally modified resulting in its movement to the nucleus and the control of transcription [24]. GAPDH is targeted by a range of reactive molecules including $\mathrm{ROS}, \mathrm{NO}$ and $\mathrm{H}_{2} \mathrm{~S}$ [21]. Here is a clear target for several modifications, which will profoundly alter the activity and function of this protein. Clearly, if one reactive molecule reacts, it 
prevents the reaction with other such signals, for example if a cysteine on GAPDH is oxidized it is less likely to be S-nitrosylated. Using techniques to look for such modifications reveals a large number of proteins for which such a competitive reaction is relevant $[19,25]$, and no doubt more will be discovered in the future.

Furthermore, there are other possible modifications of thiol groups in proteins which were not discussed in the original paper [3]. This includes S-palmitoylation (or protein S-acylation) [26]. Here the posttranslational addition involves a fatty acyl chain, often palmitate (C16:0). This modification appears to be reversible. Originally the roles of these modifications were thought to be primarily involved in the subcellular localization of the protein, which would be important for its functionality. However, more recently it has been realized that such modifications can also alter the activity of the protein more directly, so should be thought of as a cell signaling event, especially as they are reversible and again akin to phosphorylation. A key example of such an event is the increase in surface expression of AMPA receptors on the post-synaptic membranes of neurons during long-term potentiation, the major cellular model for the formation of memories [27]. Other important, and similar, modifications include SUMOylation [28] and ubiquitination [29]. The former is known to be involved in signaling, particularly involving control of the activity of transcription factors [30], and the response of cells, including neurones, to ischaemic insults [31]. Recently, a role for protein SUMOylation has been demonstrated in the regulation of secretion from neuroendocrine cells. Specifically, SUMOylation of several key proteins has been shown to be a regulator in stimulus-secretion coupling in insulin secretion in pancreatic beta-cells and neurotransmitter release in neurones. In the latter cell type, SUMOylation has been demonstrated to be involved in calcium influx in response to depolarization [32], maintenance of the secretory vesicle pool [33] and endocytosis of synaptic vesicles following release of neurotransmitter [34]. Interestingly, defects in SUMOylation have been linked to neurodegenerative diseases, including Alzheimer's disease and Huntington's disease [35] and also disorders of neurological development, including Autism Spectrum Disorder [33], thus demonstrating a key signaling role for this modification in normal brain function. Ubiquitination on the other hand was mainly thought to be involved in protein degradation and removal from the cell, but besides removing proteins involved in signaling, the direct modification of polypeptides may trigger signaling responses more directly [36].

Therefore the tenet of the original paper [3] was that $\mathrm{H}_{2} \mathrm{~S}$ was having an opposing effect on signaling compared to ROS and NO, acting as a "referee" in ROS and NO signaling. It is clear that $\mathrm{H}_{2} \mathrm{~S}$ may have an effect on the levels of other reactive compounds, may influence their accumulation and be in competition with ROS and NO for the modification of thiol groups on proteins. However, other compounds do need to be thrown into the mix too, and this will include other reactive molecules such as $\mathrm{H}_{2}$, as well as lipid-based processes such as palmitoylation and SUMOylation.

\section{References}

1. Baxter A, Mittler R, Suzuki N (2014) ROS as key players in plant stress signalling. J Exp Bot 65: 1229-1240.

2. Mur LA, Mandon J, Persijn S, Cristescu SM, Moshkov IE, et al. (2013) Nitric oxide in plants: an assessment of the current state of knowledge. AoB Plants 5: pls052.
3. Hancock JT, Whiteman M (2014) Hydrogen sulfide and cell signaling: team player or referee? Plant Physiol Biochem 78: 37-42.

4. Ritchie RH, Drummond GR, Sobey CG, De Silva TM, Kemp-Harper BK (2017) The opposing roles of NO and oxidative stress in cardiovascular disease. Pharmacol Res 116: 57-69.

5. Klotz LO, Schroeder P Sies H (2002) Peroxynitrite signaling: receptor tyrosine kinases and activation of stress-responsive pathways. Free Radic Biol Med 33: 737-743.

6. Carballal S, Trujillo M, Cuevasanta E, Bartesaghi S, Möller MN, et al. (2011) Reactivity of hydrogen sulfide with peroxynitrite and other oxidants of biological interest. Free Radic Biol Med 50: 196-205.

7. Whiteman M, Li L, Kostetski I, Chu SH, Siau JL, et al. (2006) Evidence for the formation of a novel nitrosothiol from the gaseous mediators nitric oxide and hydrogen sulphide. Biochem Biophys Res Commun 343: 303-310.

8. Schafer FQ, Buettner GR (2001) Redox environment of the cell as viewed through the redox state of the glutathione disulfide/glutathione couple. Free Radic Biol Med 30: 1191-1212.

9. Broniowska KA, Diers AR, Hogg N (2013) S-nitrosoglutathione. Biochim Biophys Acta 1830: 3173-3181.

10. Ohta S (2015) Molecular hydrogen as a novel antioxidant: Overview of the advantages of hydrogen for medical applications. Methods in Enzymol 555: 289-317.

11. Wilson HR, WhitemanVD, Hancock JT (2017) Hydrogen gas and its role in cell signaling. CAB Reviews: Perspectives in Agriculture, Veterinary Science, Nutrition and Natural Resources.

12. Hancock JT (2017) Harnessing evolutionary toxins for signaling: reactive oxygen species, nitric oxide and hydrogen sulfide in plant cell regulation. Front Plant Sci 8: 189.

13. Mata-Pérez C, Sánchez-Calvo B, Padilla MN, Begara-Morales JC, Valderrama R et al. (2017) Nitro-fatty acids in plant signaling: New key mediators of nitric oxide metabolism. Redox Biology 11: 554-561.

14. Hu LY, Hu SL, Wu J, Li YH, Zheng JL, et al. (2012) Hydrogen sulfide prolongs postharvest shelf life of strawberry and plays an antioxidative role in fruits. J Agric Food Chem 60: 8684-8693.

15. Pan LL, Liu XH, Shen YQ, Wang NZ, Xu J, et al. (2013) Inhibition of NADPH oxidase 4-related signaling by sodium hydrosulfide attenuates myocardial fibrotic response. Int J Cardiol 168: 3770-3778.

16. Kubo S, Kurokawa Y, Doe I, Masuko T, Sekiguchi F, et al. (2007) Hydrogen sulfide inhibits activity of three isoforms of recombinant nitric oxide synthase. Toxicology 241: 92-97.

17. Bright J, Desikan R, Hancock JT, Weir IS, Neill SJ (2006) ABA-induced NO generation and stomatal closure in Arabidopsis are dependent on $\mathrm{H} 2 \mathrm{O} 2$ synthesis. Plant J 45: 113-122.

18. Batthyány $\mathrm{C}$, Bartesaghi $\mathrm{S}$, Mastrogiovanni M, Lima A, Demicheli $\mathrm{V}$, et al. (2017) Tyrosine-nitrated proteins: proteomic and bioanalytical aspects. Antioxid Redox Signal 26: 313-328.

19. Jaffrey SR, Snyder SH (2001) The biotin switch method for the detection of S-nitrosylated proteins. Sci STKE 2001: pl1.

20. Belcastro E, Gaucher C, Corti A, Leroy P, Lartaud I, et al. (2017) Regulation of protein function by S-nitrosation and S-glutathionylation: processes and targets in cardiovascular pathophysiology. Biol Chem.

21. Mustafa AK, Gadalla MM, Sen N, Kim S, Mu W, et al. (2009) H2S signals through protein S-sulfhydration. Sci Signal 2: ra72.

22. Salmeen A, Barford D (2005) Functions and mechanisms of redox regulation of cysteine-based phosphatases. Antioxid Redox Signal 7: 560-577.

23. Heneberg P (2014) Reactive nitrogen species and hydrogen sulfide as regulators of protein tyrosine phosphatase activity. Antioxid Redox Signal. 20: 2191-2209.

24. Kim JJ, Lee MY (2011) p53 is not necessary for nuclear translocation of GAPDH during NO-induced apoptosis. BMB Rep 44: 782-786.

25. Williams E, Pead S, Whiteman M, Wood ME, Wilson ID, et al. (2015) Detection of thiol modifications by hydrogen sulfide. Methods Enzymol 555: 233-251. 
Citation: Hancock JT, Craig TJ, Whiteman M (2017) Competition of Reactive Signals and Thiol Modifications of Proteins . J Cell Signal 2: 1000170. doi:10.4172/2576-1471.1000170

Page 3 of 3

26. Zhang MM, Hang HC (2017) Protein S-palmitoylation in cellular differentiation. Biochemical Society Transactions 45: 275-285.

27. Lin DT, Makino Y, Sharma K, Hayashi T, Neve R, et al. (2009) Regulation of AMPA receptor extrasynaptic insertion by $4.1 \mathrm{~N}$, phosphorylation and palmitoylation. Nat Neurosci 12: 879-887.

28. Coelho-Silva L, Stephens GJ, Cimarosti H (2017) SUMOylation and calcium signalling: potential roles in the brain and beyond. Neuronal Signaling 1: (3).

29. Varshavsky A (2017) The ubiquitin system, autophagy, and regulated protein degradation. Annu Rev Biochem 86: 123-128.

30. Shalizi A, Gaudillière B, Yuan Z, Stegmüller J, Shirogane T, et al. (2006) A calcium-regulated MEF2 sumoylation switch controls postsynaptic differentiation. Science 311: 1012-1017.

31. Guo C, Hildick KL, Luo J, Dearden L, Wilkinson KA, et al. (2013) SENP3mediated deSUMOylation of dynamin-related protein 1 promotes cell death following ischaemia. EMBOJ 32: 1514-1528.
32. Girach F, Craig TJ, Rocca DL, Henley JM (2013) RIMla SUMOylation is required for fast synaptic vesicle exocytosis. Cell Rep 5: 1294-1301.

33. Tang LT, Craig TJ, Henley JM (2015) SUMOylation of synapsin Ia maintains synaptic vesicle availability and is reduced in an autism mutation. Nat Commun 6: 7728.

34. Craig TJ, Anderson D, Evans AJ, Girach F, Henley JM (2015) SUMOylation of Syntaxin1A regulates presynaptic endocytosis. Sci Rep 5: 17669.

35. Henley JM, Craig TJ, Wilkinson KA (2014) Neuronal SUMOylation: mechanisms, physiology, and roles in neuronal dysfunction. Physiol Rev 94: 1249-1285.

36. Sun L, Chen ZJ (2004) The novel functions of ubiquitination in signaling. Curr Opin Cell Biol 16: 119-126. 